\title{
LA TRAZA DE LOS ANTIGUOS RETABLOS MAYORES CLASICISTAS DE DOS IGLESIAS PARROQUIALES DE LALÍN: SANTIAGO DE CATASÓS Y SAN XOÁN DE VILANOVA
}

\author{
Por \\ FRANCISCO JAVIER NOVO SÁNCHEZ
}

\section{RESUMEN}

El escultor y entallador Juan de Villoldo, vinculado presumiblemente a una familia de artistas activa en Castilla en el último tercio del siglo XVI, se encarga, en 1586, de fabricar los retablos mayores de las iglesias parroquiales de Santiago de Catasós y San Xoán de Vilanova, pertenecientes al municipio pontevedrés de Lalín. Para ello maneja un diseño que le habían solicitado los feligreses del primero de los curatos. Dicha traza muestra el alzado de un retablo que aglutina buena parte de los distintivos de la corriente clasicista. A través de ella se evidencia su impericia en la práctica del dibujo y su inadaptación a esta nueva tendencia estética, puesto que usa elementos arquitectónicos que, como la columna abalaustrada, ya no se emplean en los últimos decenios de la referida centuria.

\section{PALABRAS CLAVE}

Juan de Villoldo, Catasós, Vilanova, Lalín, Siglo XVI, Clasicismo. 


\begin{abstract}
The sculptor Juan de Villoldo, presumably linked to an active family of artists in Castille in the last third of the $16^{\text {th }}$ Century, undertook the construction of the high altarpieces of the parish churches of Santiago de Catasós and San Xoán de Vilanova in 1586, situated in Lalín (Pontevedra). In order to do this he uses a design requested by the parishioners of the first curacy. The plan shows the elevation of an altarpiece that brings together most of the typical features of the classicist trend. Through it, there is evidence of his lack of skill at drawing and of his failure to adapt to new aesthetic tendencies, since he uses architectural elements (such as the balaustrade-style column) that had fallen into disuse in the last decades of the aforementioned century.
\end{abstract}

\title{
KEYWORDS
}

Juan de Villoldo, Catasós, Vilanova, Lalín, $16^{\text {th }}$ Century, Classicism.

El Archivo Histórico Provincial de Lugo guarda, entre su rica y variada documentación gráfica, uno de los escasos dibujos de retablos conservados en Galicia. Se trata de un diseño de 1586 del escultor y entallador Juan de Villoldo, realizado para el altar mayor de la iglesia parroquial de Santiago de Catasós y luego tomado como referente para la de San Xoán de Vilanova, feligresías pertenecientes al municipio pontevedrés de Lalín.

La ausencia de trazas originales es común a todas las artes, pues lo habitual era que fuesen utilizadas en el transcurso de las obras por artistas y clientes y, con el uso, se deteriorasen y extraviasen una vez finalizadas. Los ejemplares que han logrado sustraerse a tal práctica, y que han quedado al margen, en mayor o menor grado, de la humedad, la acción térmica y lumínica, los insectos y la rapiña, se custodian en los archivos y bibliotecas españolas, buena parte de ellos cosidos al correspondiente contrato ${ }^{1}$.

${ }^{1}$ Acerca de las causas que motivaron la insuficiencia de dibujos españoles se recomienda la lectura del estudio clásico de A. RODRÍGUEZ MỌÑINO: «Sobre la supuesta

«CUADERNOS DE ESTUDIOS GALLEGOS», Tomo L, Fascículo 116, Santiago 2003. 
Este es el caso del dibujo objeto de análisis, unido al oportuno instrumento público en la oficina del escribano de Lugo Juan Sanjurjo de Aguiar, siendo sólo una pequeña muestra de los que llegarían a dibujarse en España y Galicia en el último tercio del quinientos y buena parte del siglo $\mathrm{XVII}^{2}$.

\section{INTRODUCCIÓN HISTÓRICA}

Juan de Villoldo proviene, posiblemente, de una línea de artífices presente en tierras castellanas en el segundo tercio del quinientos, principalmente en Valladolid, Palencia, Ávila y Toledo, con alguna actuación aislada en Guadalajara y Sevilla. A dicha estirpe pertenecen, aparte de otros miembros menos afamados, su homónimo Juan de Villoldo, reconocido pintor, y el escultor Isidro de Villoldo, ambos seguidores de Alonso Berruguete ${ }^{3}$. Nuestro maestro, tal vez hijo y discípulo de Isidro, trabaja

inexistencia de dibujos antiguos españoles», Boletín de la Sociedad Española de Excursiones, LVIII, 1954, 143-149.

${ }^{2}$ La temática del dibujo en España ha sido abordada por A. E. PÉREZ SÁNCHEZ: Historia del dibujo en España. De la Edad Media a Goya, Madrid, 1986. Buena parte de los diseños de retablos españoles y gallegos de tal época se recogen y analizan en los trabajos, de obligatorio manejo, de E. M. SANTIAGO PÁEZ: Dibujos de arquitectura y ornamentación de la Biblioteca Nacional. Siglos XVI y XVII, Madrid, 1991 y M. TAÍN GUZMÁN: Trazas, planos y proyectos del Archivo de la Catedral de Santiago, A Coruña, 1999.

${ }^{3}$ Sobre estos dos maestros y su producción en las referidas ciudades véanse J. A. CEÁN BERMÚDEZ: Diccionario histórico de los más ilustres profesores de las Bellas Artes en España, V, Madrid, 1800, 260-264; M. E. GÓMEZ MORENO: «Isidro de Villoldo, escultor», Boletín del Seminario de Arte y Arqueología, VIII, 1942, 139-150; E. GARCÍA CHICO: Documentos para el estudio del Arte en Castilla. Pintores, III, 1, Valladolid, 1946, 12, 14, 41, 42, 99 y 100-110; J. M. ${ }^{\text {a }}$ CAAMAÑO MARTíNEZ: «Juan de Villoldo", Boletín del Seminario de Arte y Arqueología, XXXII, 1966, 71-88; J. M. ${ }^{a}$ PARRADO DEL OLMO: «Nuevas atribuciones a Juan de Villoldo», Boletín del Seminario de Estudios de Arte y Arqueología, XLII, 1976, 291-305; J. J. MARTÍN GONZÁLEZ (dir.): Inventario artístico de Palencia y su provincia, I, Madrid, 1977, 19, 21, 38, 54, $81,115,165,189,194,197,215,217,221,230,264,287$ y 298; J. J. MARTÍN GONZÁLEZ (dir.): Ob. cit., II, 7, 165, 258 y 271; J. M. ${ }^{\text {a }}$ PARRADO DEL OLMO: «Testamento y otros datos de Juan de Villoldo», Publicaciones de la Institución Tello Téllez de Meneses, 42, 1979, 133-152; J. M. ${ }^{a}$ PARRADO DEL OLMO: Los escultores seguidores de Berruguete en Palencia, Valladolid, 1981, 113, 175, 186 y 276; J. R. BUENDÍA y

«CUADERNOS DE ESTUDIOS GALLEGOS», Tomo L, Fascículo 116, Santiago 2003. 
en Galicia en el último cuarto del siglo XVI, cuando menos en Padrón ${ }^{4}$, Lugo $^{5}$, Mondoñedo ${ }^{6}$, Pontevedra ${ }^{7}$ y Lalín ${ }^{8}$.

Pedro López, en nombre de los feligreses de Catasós, parroquia vinculada al arciprestazgo de Deza y dependiente del obispado de Lugo, aprovecha la estancia de Villoldo en la capital lucense para encomendarle, el 20 de agosto de 1586, la delineación y ejecución de un retablo para el altar mayor de su templo parroquial:

A. ÁVILA: «La intervención de Juan de Villoldo en la provincia de Guadalajara. El retablo de Renera», Boletín del Seminario de Arte y Arqueología, XLVIII, 1982, 233242; I. MATEO GÓMEZ: «Dos tablas de Juan de Villoldo y un retablo toledano de su círculo», Boletín del Seminario de Estudios de Arte y Arqueología, L, 1984, 416-421; J. M. ${ }^{a}$ PARRADO DEL OLMO: «Juan de Villoldo», en Jornadas sobre el Renacimiento en la provincia de Palencia, Palencia, 1987, 57-72; y M. I. RODRÍGUEZ QUINTANA: El obrador de escultura de Rafael de León y Luis de Villoldo, Toledo, 1991.

${ }^{4}$ Siendo vecino de la villa de Padrón, contrata con el entallador flamenco Aimon Pourselet, con fecha del 21 de mayo de 1576, el asiento de un retablo que le habían encargado para la iglesia de Santa María de Iria Flavia. El 26 de junio del mismo año dejan sin efecto dicho acuerdo, siendo desconocidas las causas de tal decisión [Archivo de la Catedral de Santiago (A.C.S.), Varia, I, 52, Libro 713. Cfr. P. PÉREZ COSTANTI: Diccionario de artistas que florecieron en Galicia durante los siglos XVI y XVII, Santiago, 1930, 445-447 e 569]. Sobre esta actuación véase M. ${ }^{\text {a }}$ T. RÍOS MIRAMONTES: «La colegiata de Santa María de Iria, de Padrón», Archivo Ibero-Americano, XLIII, 171-172, 1983, 364-380.

${ }^{5}$ El 9 de julio de 1585, habitando en la villa de Redondela, llega a un acuerdo con el prior del convento de Santo Domingo de Lugo, fray Pedro de Salcedo, para que le pague por adelantado, a cuenta del precio de un retablo que se le había adjudicado para la iglesia de dicho cenobio, treinta ducados, pues «tenía necesidad de ir a buscar a su mujer y traer su familia» [Archivo Histórico Provincial de Lugo (A.H.P.L.), Distrito Notarial de Lugo, Pedro López de Luaces, 1585. Cfr. P. PÉREZ COSTANTI, Pablo: Ob. cit, 569-570].

${ }^{6}$ Para el retablo que se estaba ejecutando para el oratorio del Consistorio mindoniense labrará «tres ymágenes, en que a de aber un crucufijo y una Nuestra Señora y otra de San Sebastián de tres palmos y medio» [Archivo Histórico Municipal de Mondoñedo (A.H.M.M.), Actas Capitulares (1586-1595), fol. 24v. Cit. P. PÉREZ COSTANTI, Pablo: Ob. cit., 570].

${ }^{7}$ En 1589 ajusta en 20 ducados la fábrica de un retablo con destino a la capilla de Ánimas de la basílica de Santa María la Grande de Pontevedra [Archivo Histórico Provincial de Pontevedra (A.H.P.P.), Protocolos Notariales, Distrito de Pontevedra, Bartolomé García, 1589. Cfr. P. PÉREZ COSTANTI: Ob. cit., 570-571].

${ }^{8}$ Cuando se le confía la fabricación de los dos retablos de Lalín habitaba en Lugo. Cfr. P. PÉREZ COSTANTI: Ob. cit., 570 y los documentos del apéndice adjunto.

«CUADERNOS DE ESTUDIOS GALLEGOS», Tomo L, Fascículo 116, Santiago 2003. 
«en que a de auer su costodia çerrada en el pedestal y luego arriba una caxa con una ymajen de Nuestra Señora, y a los lados otras dos caxas para otras dos ymáxines, y arriba otra caxa con una ymaxen de Dios Padre que sea de medio bulto, con su fontespiz arriba y con sus serafines, que sean tres entre las molduras, y seis pilares y la más obra y moldura».

Se fabricará y asentará en el plazo de seis meses, cuyo coste, remunerado en tres cuotas, será el que «tasaren dos personas, quel uno dellos a de ser el señor canónigo Robles, bisitador, y el otro a de ser el que nonbrare el cura y feligreses de la dicha yglesia». En el precio pactado se incluye el importe y transporte de las maderas necesarias de castaño y nogal y el estipendio del maestro. En cualquier caso, la cuantía de las dos primeras pagas es fija y asciende cada una a catorce ducados ${ }^{9}$.

Entre tanto, los parroquianos de Vilanova, curato inmediato a Catasós e incluido en la misma demarcación eclesiástica, deciden renovar el retablo de la testera del presbiterio de su iglesia, en el cual:

«a de aber su custodia en el pedestal çerrada, y luego arriba una caxa con una ymajen de San Juan y a los lados otras dos caxas para otras dos ymáxines, y las ymáxines que le dixeren, que sea una de Nuestra Señora y la otra la que el mayordomo dixere, y arriba otra caxa con una ymajen de Dios Padre que sea de medio bulto, con su fontespiz arriba y con sus serafines, que sean tres entre las molduras y sus pilares, y la más obra y molduras».

Gregorio de Navallos, en representación de los habitantes de esta última feligresía, suscribe el contrato de ejecución con Villoldo el 30 de agosto del referido año. En él se establece un intervalo de seis meses para su entrega y ensamblaje y un importe de cuarenta ducados, abonables en tres plazos, comprendiendo en el mismo el material leñoso, su traslado a la obra y la retribución del trabajo. Ambas partes no tuvieron más que seguir como

${ }^{9}$ Archivo Histórico Provincial de Lugo (A.H.P.L.), Protocolos Notariales, Distrito de Lugo, Juan Sanjurjo de Aguiar, 1586, fols. 336r-337r, sig.: 15-2. Cfr. Documento 1 del apéndice adjunto.

«CUADERNOS DE ESTUDIOS GALLEGOS», Tomo L, Fascículo 116, Santiago 2003. 
patrón la «traça, que está en poder de my, scrivano, para la iglesia de Santiago de Catasós» ${ }^{10}$.

\section{LA TRAZA}

El dibujo da a conocer un mueble contrarreformista ${ }^{11}$ de planta lineal, pues sus columnas, sin apenas resalte, se sitúan en un mismo plano. Su alzado consta de banco, cuerpo único dividido en tres calles y ático (Fig. 1). La predela presenta cuatro netos con sus caras delanteras hundidas, entre los cuales se disponen tres entrepaños rectangulares. El central, ligeramente más ancho que los laterales, se reserva para el sagrario, formado por dos columnillas abalaustradas sobre las que descansa un arco de

${ }^{10}$ A.H.P.L., Protocolos Notariales. Distrito de Lugo, Juan Sanjurjo de Aguiar, 1586, fols. 362r-363r, sig.: 15-2. Cfr. Documento 2 del apéndice adjunto.

${ }^{11}$ Los términos «contrarreformista», «romanistå», «clasicista» $\mathrm{y}$ «manierista» han sido utilizados por los historiadores del arte, con mayor o menor acierto, para referirse a la retablística ejecutada, aproximadamente, desde la celebración del Concilio de Trento hasta el advenimiento del Barroco. De sus logros bibliográficos, consagrados preferentemente al estudio de la actividad escultórica y la producción de retablos en el norte de España, destacan los siguientes títulos: J. CAMÓN AZNAR: El escultor Juan de Anchieta, Pamplona, 1943; J. J. MARTÍN GONZÁLEZ: «Precisiones sobre Gaspar Becerra», Archivo Español de Arte, 1969, 327-357; S. ANDRÉS ORDAX: El foco de escultura romanista de Miranda de Ebro. Pedro López de Gámiz y Diego de Marquina, Valladolid, 1974; S. ANDRÉS ORDAX: El escultor López de Larrea, Vitoria, 1976; G. M. BORRÁS GUALIS: Juan Miguel Orliens y la escultura romanista en Aragón, Zaragoza, 1980; J. M. PALOMERO PÁRAMO: «El manierismo romanista en la escultura sevillanà», en Actas del III Congreso Español de Historia del Arte, Sevilla, 1980, 163-166; J. A. BARRIO LOZA: La escultura romanista de La Rioja, Madrid, 1981; M. ${ }^{a}$ D. VILA JATO: Escultura manierista, Santiago, 1983; C. DÍEZ JÁVIZ: Pedro López de Gámiz, escultor mirandés del siglo XVI, Miranda de Ebro, 1985; M. ${ }^{\mathrm{a}}$ C. GARCÍA GAÍNZA: La escultura romanista en Navarra. Discipulos y seguidores de Juan de Anchieta, Pamplona, 1986; J. ARRANZ ARRANZ: La escultura romanista en la diócesis de Osma-Soria, Soria, 1986; M. ${ }^{a}$ C. GARCÍA GAÍNZA: «El retablo romanista», Imafronte, 3-5, 1987-89, 85-98; P. L. ECHEVERRÍA GOÑI y C. DÍEZ JÁVIZ: «López de Gámiz y Anchieta comparados. Las claves del romanismo norteño», Príncipe de Viana, 1988, 477-534; J. M. RAMÍREZ MARTÍNEZ: «Escultores romanistas riojanos», Antiquaria, 57, 1988, 36-40; M. A. GONZÁLEZ GARCÍA: «Pedro de Arbulo Marguvete y Gaspar de Becerra», Príncipe de Viana, 1991, 211-216; J. J. VÉLEZ CHAURRI: Becerra, Anchieta y la escultura romanista, Madrid, 1992; y J. J. POLO SÁNCHEZ: La escultura romanista y contrarreformista en Cantabria (c.1590-1660), Santander, 1994.

«CUADERNOS DE ESTUDIOS GALLEGOS», Tomo L, Fascículo 116, Santiago 2003. 


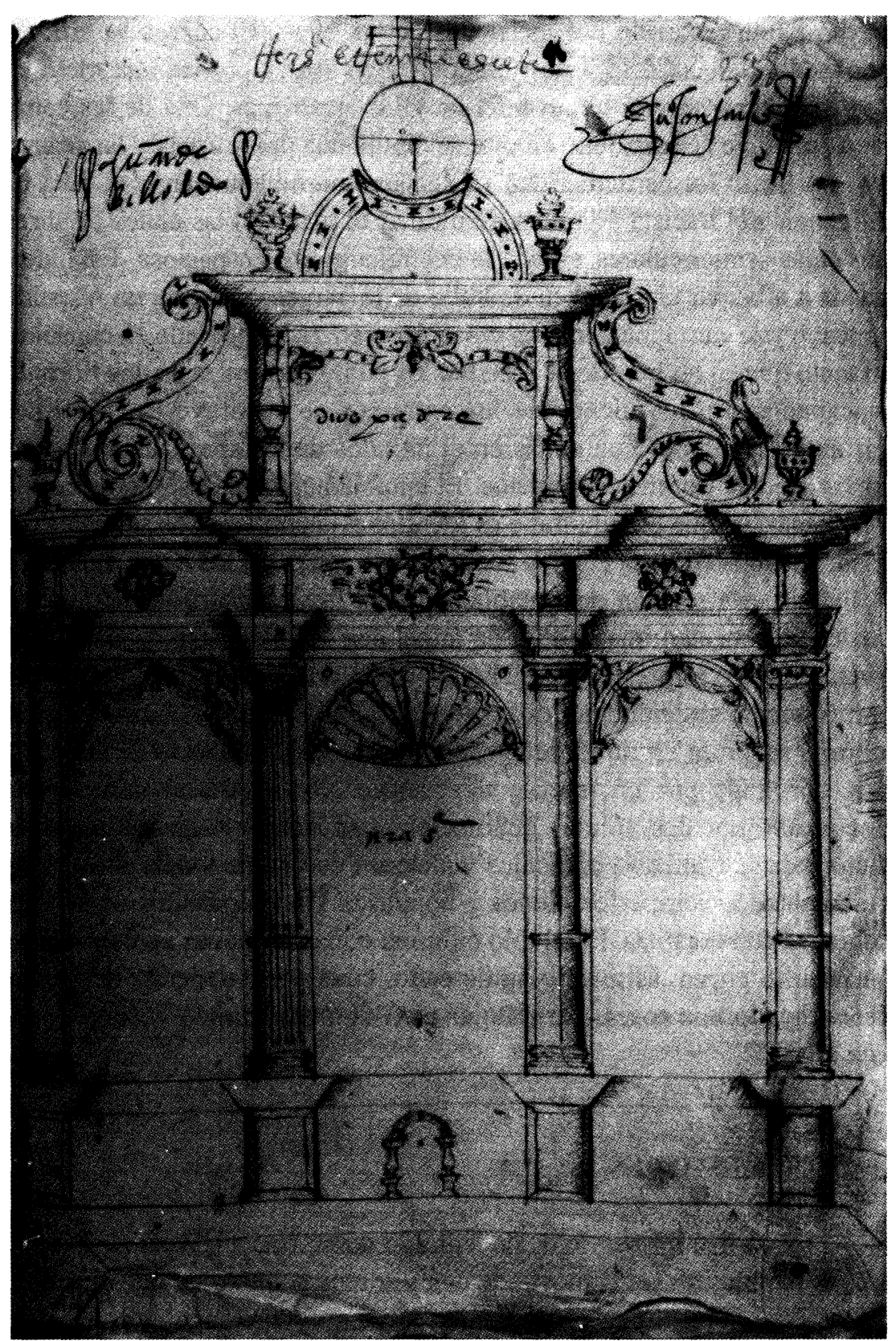

Fig. 1.- Juan de Villoldo. Traza de los retablos mayores de las iglesias parroquiales de Santiago de Catasós y San Xoán de vilanova.

«CUADERNOS DE ESTUDIOS GALLEGOS», Tomo L, Fascículo 116, Santiago 2003. 
medio punto recorrido por incisiones geométricas. El cuerpo se articula por medio de cuatro soportes jónicos, cuyos fustes poseen una moldura de separación entre el tercio inferior y los superiores. Una de las cañas muestra doble acanaladura, en otra se dibuja una única estría y las restantes son lisas. Tal particularidad se debe, presumiblemente, a la falta de diligencia del tracista a la hora de ultimar el plan. En las calles se abren tres cajas semicirculares, siendo la central algo más espaciosa. Ésta, destinada a albergar una imagen de bulto de la Virgen, presenta un respaldo cóncavo y se cierra mediante un cascarón avenerado montado en consolas, en tanto que en las enjutas se esbozan los puntos centrales de dos florones inacabados. En los nichos de los extremos se sustituye la vieira por cortinajes recogidos con cintas en el intradós de los arcos, delineándose en las enjutas florones completos. El entablamento es desproporcionado e inexacto, ya que el arquitrabe es idéntico a la cornisa. Los salientes del friso, situados en línea con los soportes, son iguales a los netos del banco y dividen esta sección del entablamento en tres compartimentos, en los cuales se abocetan una cabeza de ángel con las alas desplegadas y dos tarjas. El ático lo preside un nicho apaisado, sobre el cual se dispone un cornisamento sostenido por dos columnas abalaustradas. En su interior se labrará, según la escritura de concierto, una figura relivaria de Dios Padre, coronada por un motivo decorativo consistente en una tarjeta flanqueada por dos volutas guarnecidas con roleos. A ambos lados de dicha caja se emplazan pináculos y aletones con doble vuelta de caracol, ornamentados con perforaciones y hojarasca y acompañados de volutas cubiertas con escamas. El retablo culmina con dos nuevas acróteras y un tambanillo curvo, asimismo agujereado, cuya parte superior se hunde, describiendo una rosca, para alojar el Globo del Mundo coronado por una cruz.

\section{CONCLUSIONES}

Al requerirse los servicios de Villoldo como tracista y constructor de ambos retablos queda demostrada una vez más la teoría de que el grueso de la actividad artística en la Galicia del quinientos recae en maestros foráneos, especialmente de origen castellano, flamenco y luso. A esta monopolización no es ajena la retablística, con representantes del calado de

«CUADERNOS DE ESTUDIOS GALLEGOS», Tomo L, Fascículo 116, Santiago 2003. 
Cornelis de Holanda, Maestro de Sobrado, Juan Bautista Celma, Juan de Angés el Mozo, Gregorio Español, Alonso Martínez Montánchez y Juan de Muniategui ${ }^{12}$. Buena parte de los artífices que trabajan en territorio galaico en el tercer tercio de dicha centuria, desde Celma hasta Muniategui, y entre los que se encuentra Villoldo, integran una generación que ha asimilado, y superado, los criterios estilísticos impuestos por Juan de Juni, que es tomado como modelo, adoptando el espíritu clasicista emanado de las producciones de Esteban Jordán ${ }^{13}$ y Gaspar Becerra, encarnado, por su valor de prototipo, en el retablo mayor de la Catedral de Astorga ${ }^{14}$.

Villoldo es, por otra parte, un maestro de segunda fila que nada tiene que ver con la calidad exhibida por alguno de sus hipotéticos parientes, pues utiliza fórmulas estilísticas arcaizantes ya en desuso, en concreto la columna abalaustrada. Asimismo, demuestra su impericia en el ejercicio del dibujo, ya que maneja incorrectamente las proporciones, las líneas son muy elementales y carentes de equilibrio, persisten algunos trazos preparatorios y faltan otros de enorme relevancia. Tales factores rebajan la traza, que se supone definitiva, a la categoría de mero bosquejo.

\footnotetext{
${ }^{12}$ Sobre la vida y el currículum profesional de tales escultores y entalladores véanse P. PÉREZ COSTANTI: Ob. cit., 25, 26, 115-134, 158, 159, 287-293 y 365-367; M. CHAMOSO LAMAS: «Juan Bautista Celma. Un artista del siglo XVI», Cuadernos de Estudios Gallegos, XII, 1957, 179-195; M. CHAMOSO LAMAS: «El escultor Cornielles de Holanda. Introducción al arte del Renacimiento en Galicia», Abrente, 5, 1973, 7-30; J. J. MARTÍN GONZÁLEZ y J. GONZÁLEZ PAZ: El maestro de Sobrado, Ourense, 1986; J. J. MARTÍN GONZÁLEZ: «Juan de Juni y Juan de Angés el Mozo, en Orense», Cuadernos de Estudios Gallegos, XVII, 51, 1962, 68-82; y M.. D. VILA JATO: Ob. cit., 2345, 55-71, 83-109 y 129-159.

${ }^{13}$ En torno a este maestro véase la monografía clásica de J. J. MARTÍN GONZÁLEZ: Esteban Jordán, Valladolid, 1952.

${ }^{14}$ Acerca del retablo del altar mayor de dicha Basílica leonesa y su valor como pauta véanse las recientes aportaciones bibliográficas de M. ${ }^{a}$ C. GARCÍA GAIÍNZA: «El retäblo de Astorga y la difusión del romanismo», Boletín del Museo e Instituto "Camön Aznar», LXXVII-LXXIX, 1999, 177-206; y M. SERRANO MARQUÉS: «Gaspar Becera y la introducción del romanismo en España", Boletín del Museo e Instituto "Camón Aznar», LXXVII-LXXIX, 1999, 207-239.
}

«CUADERNOS DE ESTUDIOS GALLEGOS», Tomo L, Fascículo 116, Santiago 2003. 


\section{APÉNDICE DOCUMENTAL}

\section{(1)}

1586, agosto, 20. Lugo.

Contrato firmado entre Pedro López, como delegado del vecindario de Santiago de Catasós, y el escultor y entallador Juan de Villoldo para fabricar un retablo para el altar mayor de la iglesia parroquial.

A.H.P.L., Protocolos Notariales, Distrito de Lugo, Juan Sanjurjo de Aguiar, 1586, fols. 336r-337r, sig.: 15-2.

En la çiudad de Lugo, a ueinte días del mes de agosto de mill e quinientos y ochenta y seis años, en presencia de mí scriuano e testigos de yuso hescritos paresçieron presentes Juan de Villoldo, entallador, residiente en esta çiudad, por sí, de la una parte, y Pedro López, uezino de la feligresía de Santiago de Catasós, que es en el arçedianazgo de Deza desta dióçesis de Lugo, por sí y en nonbre de la dicha yglesia de Santiago dẻCatasós y uezinos y feligreses della, por quien se obligó y prestó caución de rato, açiendo como hizo de deuda axena suya propia, de la otra. Y se conçertaron en esta manera: quel dicho Juan de Villoldo a de azer un retablo para la dicha yglesia de Santiago de Catasós que sea del tamaño de la Capilla Mayor de la dicha yglesia y que corresponda con la dicha Capilla y Altar del tamaño y proporçión de la mesma Capilla, en que a de auer su costodia çerrada en el pedestal y luego arriba una caxa con una ymajen de Nuestra Señora, y a los lados otras dos caxas para otras dos ymáxines, y arriba otra caxa con una ymaxen de Dios Padre que sea de medio bulto, con su fontespiz arriba y con sus serafines, que sean tres entre las molduras, y seis pilares y la más obra y moldura según hestá señalada en la traza, que queda firmada del dicho Juan de Billoldo en poder de my scriuano. Y para ello el dicho Pedro López e más feligreses le an de dar la madera que sea nesçesaria puesta al pie de la obra, y se dixo que se entiende quel dicho Juan de Billoldo a de poner toda la madera $/^{336 v}$ que sea muy buena de castaño y nogal a su costa, y dar echo y asentado el dicho retablo e ymáxines buena y perfetamente dende oy día en seis meses primeros seguientes. Por todo lo qual se le a de pagar lo que tasaren dos personas, quel uno dellos a de ser el señor canóni- 
go Robles, bisitador, y el otro a de ser el que nonbrare el cura y feligreses de la dicha yglesia, y se le a de pagar carreto y echura y madera y todo lo demás del dicho retablo en esta manera: catorçe ducados luego dentro de quinze días, y otros catorçe teniendo echo la mytad de la obra y lo más restante en que fuere tasada la dicha obra el día que la diere acabada y asentada la dicha obra, y se le an de dar los dichos marauedís de las dichas dos pagas primeras puestas en esta çiudad y lo más que fuere tasado en la dicha yglesia de Catasós el día que diere acabada y asentada la dicha obra. Y el dicho Juan de Billoldo se obligó con su persona y uienes, muebles e rayçes, auidos y por auer, de azer la dicha obra e ymágines buena y perfeta y darla puesta y asentada dentro del dicho término. Y el dicho Pedro López se obligó con su persona e uienes, muebles y rayçes, auidos e por auer, de pagar los dichos marauedís de suso declarados a los dichos plaços, con las costas e daños que sobre ello se seguieren y recreçieren. E para que lo cunplirán todas partes, cada uno por lo que le toca según dicho es dixeron que daban e dieron todo su poder cunplido a todas e qualesquiera justiçias e jueçes de los Reynos y Señoríos de Su Magestad, ante quien hesta carta paresçiere y dello fuere pedido cunplimyento de justiçia ${ }^{\beta 37 \mathrm{r}}$ a la jurisdicçión, de las quales y de cada una dellas dixeron se sometían y sometieron con las dichas sus personas e uienes, renunçiando como renunçiaron su propio fuero, jurisdicçión e domeçilio e la ley sid conbenerid de jurisditione onyum judicum para que las dichas justiçias y cada una dellas se lo agan cunplir bien y a tan cumplidamente como si esta carta y lo en ella contenido fuese sentençia difinytiua de juez conpetente, pasada en cosa juzgada, sobre lo qual renunçiaron todas e qualesquier otras leis, fueros y derechos hescritos e no hescritos de que se puedan aprouechar, e la ley que dize que general renunçiaçión de leis fecha no bala. E otorgaron la presente carta ante my, scriuano, e testigos, y el dicho Juan de Billoldo lo firmó de su nonbre y el dicho Pedro López por no sauer firmar rogó a Pedro Sanjurjo, hijo de mí, scriuano, firme por él de su nonbre, y estando presentes por testigos el dicho que firmó, e Juan de Castro, uezino de San Salbador de Ladra, e Lorenço Calbo, clérigo de Santa Marina de Cangas, e yo scriuano doy fe conozco al dicho Juan de Villoldo, e porque no conozco al dicho Pedro López real juramento del dicho Lorenço Calbo y Grauiel de Puga, scriuano, los queles juraron le conosçían y era él mismo.

Como testigo, don Pedro Sanjurjo. Juan de Billoldo. Pasó ante my, Juan Sanjurjo, scriuano. 
(2)

1586, agosto, 30. Lugo.

Contrato suscrito entre Gregorio de Navallos, en representación de los feligreses de San Xoán de Vilanova, y Juan de Villoldo para construir un retablo con destino al altar mayor del templo parroquial

A.H.P.L., Protocolos Notariales, Distrito de Lugo, Juan Sanjurjo de Aguiar, 1586, fols. 362r-363r, sig.: 15-2.

En la ciudad de Lugo, a treynta días del mes de agosto de myll y quinientos y ochenta y seys, en preseçia de my el scribano y testigos de yuso scritos paresçieron presentes Juan de Billoldo, entallador, residiente en esta çiudad, por sí, de la una parte, y Gregorio de Naballos, vezino de la feligresía de San Juan de Villanoba, que es en tierra de Deça, de la otra, por sí y en nonbre de la dicha yglesia de San Juan de Villanoba y de los vecinos y feligreses della, por quien se hobligó y prestó cauçión de rato, aziendo como hizo de deuda ajena suya propia. Y se concertaron en esta manera: quel dicho Juan de Villoldo a de azer un retablo para la yglesia de San Juan de Villanoba que sea del tamaño de la Capilla Mayor de la dicha yglesia y que corresponda con la dicha capilla y altar del tamaño y proporçión de la mysma capilla, en que a de aber su custodia en el pedestal çerrada, y luego arriba una caxa con una ymajen de San Juan y a los lados otras dos caxas para otras dos ymáxines, y las ymáxines que le dixeren, que sea una de Nuestra Señora y la otra la que el mayordomo dixere, y arriba otra caxa con una ymajen de Dios Padre que sea de medio bulto, con su fontespiz arriba y con sus serafines, que sean tres entre las molduras y sus pilares, y la más obra y molduras según hestá señalada en una traça, que está en poder de my scrivano, para la iglesia de Santiago de Catasós. Y el dicho Juan de Billoldo a de poner toda la madera de castaño e nogal que sea nescesaria y dar echo e asentado el dicho retablo e ymáxines, buena y perfectamente, de oy día en seis meses primeros seguientes, con que se le a de pagar por ella asta en quenta de quarenta ducados, y que si el dicho Juan de Billoldo quisiere quitar algo de las molduras lo pueda hazer añadiendo o quitando atento que no se le a de pagar más de los quarenta ducados aunque sea tasada en más, lo qual an de tasar dos personas, quel uno dellos a de ser el señor canónigo Pedro de Robles, besitador general deste obispado, y el otro el que nonbrare

«CUADERNOS DE ESTUDIOS GALLEGOS», Tomo L, Fascículo 116, Santiago 2003. 
el cura e feligreses de la dicha yglesia, y se le a de pagar carreto y hechura e madera e todo lo demás de dicho retablo ${ }^{\beta 62 v}$ en esta manera: catorze ducados dentro de quinze días primeros seguientes, y otros catorze ducados dende a tres meses luego seguientes y lo más restante en que fuere tasada la dicha obra el día que la diere acabada y asentada. Y le an de dar los maravedís de las dos pagas primeras puestas en esta ciudad a los dichos plazos y los más que fuere tasado en la dicha iglesia de San Juan de Bilanoba el día que diere acabada y asentada la dicha obra. Y el dicho Juan de Billoldo se obligó con su persona e bienes muebles e raízes, abidos e por aber, de hazer la dicha obra e ymáxines, buena y perfeta, y darla puesta y asentada en la dicha iglesia dentro del dicho término. Y el dicho Gregorio de Naballos se obligó con su persona e bienes muebles e raízes, abidos e por aber, de pagar los dichos maravedís de suso declarados a los dichos plazos con las costas e daños e daños que sobre la cobrança dellos se seguieren e recreçieren. $\mathrm{E}$ para que lo cumplirán según dicho es todas partes e cada una por lo que le toca dixeron que daban e dieron todo su poder cunplido a todas e qualesquiera justiçias e juezes de los reynos e señoríos de Su Magestad ante quien esta carta paresçiere e della fuere pedido cunplimiento de justiçia a la jurisdiçión. De las quales e de cada una dellas dixeron se sometían e sometieron con las dichas sus personas e bienes, renunçiando como renunçiaron su propio fuero, jurisdiçión, e domiçilio e la ley sid conbenerit juredisçioni oniun judicun, para que los dichos juezes se lo agan cunplir bien e tan cunplidamente como si esta carta e lo en ella contenido fuese sentençia difinitiva de juez conpetente, por ellos pedida e consentida e no apelada ${ }^{\beta 63 \mathrm{r}}$ e pasada en cosa juzgada, sobre lo qual renunçiaron todas e qualesquier otras leys, fueros e derechos, hescritos e no hescritos, de que se puedan aprobechar, e la ley que dize que general renunçiaçión de leys fecha no bala. E otorgaron la presente carta ante mí scrivano e testigos de yuso hescritos, y el dicho Juan de Billoldo lo firmó de su nonbre y el dicho Gregorio de Naballos por no saber firmar rogó a Lorenço Calbo, clérigo, cura de San Juan de Palmoy, firme por él de su nonbre, estando presentes por testigos el dicho Lorenço Calbo e Juan da Bila, vezino de Santa María de Donramiro, e Gregorio da Pena, vezino del monasterio de Bilar de Donas, e yo scrivano doy fe conozco al dicho Juan de Billoldo, e porque no conozco al dicho Gregorio de Naballos real juramento de los dichos Lorenço Calbo e Juan da Bila, los quales juraron le conoçían e que hera el mismo aquí contenido.

Lorenço Calbo, clérigo. Juan de Billoldo. Pasó ante mí, Juan Sanjurjo, scrivano.

«CUADERNOS DE ESTUDIOS GALLEGOS», Tomo L, Fascículo 116, Santiago 2003. 